\title{
OPTIMAL FLOW RATES FOR INTEGRATED CARDIOPLEGIA
}

Vivek Rao, MD

Gideon Cohen, MD

Richard D. Weisel, MD

Noritsugu Shiono, MD, $\mathrm{PhD}$

Yoshiki Nonami, MD, PhD

Susan M. Carson, AHT

Joan Ivanov, RN, MSc

Michael A. Borger, MD

Robert J. Cusimano, MD

Donald A. G. Mickle, MD
Background: Antegrade cardioplegic delivery may be impaired by coronary occlusions, whereas retrograde delivery of cardioplegic solution may be inhomogeneous, leading to an accumulation of lactate and hydrogen ions, the products of anaerobic metabolism. Integrated cardioplegia using continuous retrograde cardioplegia and antegrade infusions into completed vein grafts washes out metabolites accumulated in regions inadequately perfused by retrograde cardioplegia alone. To determine the flow rates required to achieve the greatest washout, we compared a high flow rate (200 $\mathrm{ml} / \mathrm{min})$ to a low flow rate $(100 \mathrm{ml} / \mathrm{min})$. Methods: Twenty patients scheduled for isolated coronary bypass surgery were prospectively randomized to compare two flow rates for integrated cardioplegic protection using tepid $\left(29^{\circ} \mathrm{C}\right)$ blood cardioplegia. Arterial and coronary sinus blood samples were collected to evaluate myocardial metabolism. After antegrade arrest, cardioplegic solution was delivered by coronary sinus perfusion and simultaneous infusions into each completed vein graft at either high or low flow. Results: Increasing from low to high flow increased the washout of lactate and hydrogen ions during the aortic crossclamp period. Two hours after crossclamp removal, ventricular function was better in the high flow group. Conclusions: Tepid retrograde cardioplegia resulted in an accumulation of toxic metabolites. The addition of antegrade vein graft infusions at a flow rate of $100 \mathrm{ml} / \mathrm{min}$ resulted in a washout of these metabolites. A flow rate of $200 \mathrm{ml} / \mathrm{min}$ further improved this washout and resulted in improved ventricular function. An integrated approach to myocardial protection using a flow rate of $200 \mathrm{ml} / \mathrm{min}$ may improve the results of coronary bypass surgery. (J Thorac Cardiovasc Surg 1998;115:226-35)
$\mathrm{C}$ ritical coronary stenoses may limit the delivery of antegrade cardioplegia to ischemic regions of the heart, particularly when revascularization with the

From the Division of Cardiovascular Surgery and the Department of Clinical Biochemistry; The Toronto Hospital and the University of Toronto. Toronto, Ontario, Canada.

Supported by the Medical Research Council of Canada (Grant MT9829). V.R. is a Pharmaceutical Roundtable Research Fellow of the Heart and Stroke Foundation of Canada. G.C. and M.A.B. are Research Fellows of the Heart and Stroke Foundation of Canada. R.D.W. is a Career Investigator of the Heart and Stroke Foundation of Ontario.

Presented in part at the Sixty-ninth Scientific Sessions of the American Heart Association, New Orleans, La., Nov. 9-13, 1996.

Received for publication Nov. 29, 1996; revisions requested March 7, 1997; revisions received August 27, 1997; accepted for publication Sept. 16, 1997.

Address for reprints: Richard D. Weisel, MD, EN 14-215, The Toronto Hospital, Toronto, Ontario, Canada M5G 2C4.

Copyright (C) 1998 by Mosby, Inc.

$0022-5223 / 98 \$ 5.00+0 \quad \mathbf{1 2 / 1 / 8 6 1 8 5}$ internal thoracic artery prevents vein graft infusions to the left anterior descending coronary artery. Retrograde delivery of cardioplegic solution through the coronary sinus has been proposed to be a superior method of myocardial protection ${ }^{1-3}$; however, capillary perfusion may be inadequate. ${ }^{4-7}$

Hypothermia $\left(10^{\circ} \mathrm{C}\right)$ may provide additional protection but may prevent the resuscitation of the ischemic myocardium. ${ }^{7}$ Warm $\left(37^{\circ} \mathrm{C}\right)$ blood cardioplegia, delivered either antegradely or retrogradely, permits earlier recovery of ventricular function, ${ }^{8}$ but results in greater anaerobic myocardial metabolism. Interruptions in the delivery of warm blood cardioplegia may lead to normothermic myocardial ischemia. ${ }^{9}$ We have recently shown that tepid $\left(29^{\circ} \mathrm{C}\right)$ blood cardioplegia, given either antegradely or retrogradely, reduced anaerobic lactate and acid release during cardioplegic arrest and preserved ventricular function compared with either warm or cold cardioplegia. ${ }^{10}$ However, tepid retrograde cardioplegia resulted in a significant accumulation of 
lactate and hydrogen ions, the products of anaerobic metabolism.

An integrated approach to myocardial protection with both antegrade and retrograde delivery has been used to optimize cardioplegic perfusion. ${ }^{11-16}$ We found that alternating retrograde perfusion with intermittent antegrade infusions into the aortic root effectively washed out lactate and acid that accumulated during retrograde delivery. ${ }^{14}$ Retrograde perfusion with simultaneous antegrade infusions into each completed vein graft resulted in similar protection to the alternating technique and was technically easier. ${ }^{16}$

We found that increasing normothermic retrograde flow rates from 50 to $200 \mathrm{ml} / \mathrm{min}$ decreased anaerobic lactate production. ${ }^{17}$ Further increases in flow to 300 or $500 \mathrm{ml} / \mathrm{min}$ increased the shunt flow without decreasing lactate production. This study was designed to compare delivery of tepid retrograde cardioplegia with simultaneous antegrade infusions into completed vein grafts at high flow (200 $\mathrm{ml} / \mathrm{min}$ ) versus low flow $(100 \mathrm{ml} / \mathrm{min})$. We hypothesized that tepid retrograde cardioplegia alone would result in less accumulation of potentially toxic lactate and hydrogen ions than warm retrograde cardioplegia. The addition of antegrade vein graft infusions may wash out any accumulated metabolites, and increasing the flow rate from 100 to 200 $\mathrm{ml} / \mathrm{min}$ may further improve cardioplegic delivery to the ischemic myocardium.

\section{Material and methods}

Patient population. Twenty patients scheduled for isolated coronary artery bypass grafting by one surgeon agreed to participate in a study of alternative cardioplegic techniques. All patients signed a consent form approved by the Human Experimentation Committee. One patient in the low flow group was excluded intraoperatively because of an inability to insert a retrograde coronary sinus cannula. The preoperative characteristics of the remaining 19 patients are displayed in Table I.

Operative technique. Cardiopulmonary bypass was established using an ascending aortic cannula and a single, two-stage right atrial cannula. During bypass the hematocrit was between $20 \%$ and $25 \%$; pump flows were between 2.0 and $2.5 \mathrm{~L} / \mathrm{min}$ per square meter; and the mean arterial pressure was maintained between 50 and 60 $\mathrm{mm} \mathrm{Hg}$, with the administration of sodium nitroprusside or phenylephrine hydrochloride as required. Systemic perfusion was not actively cooled or warmed, but the body temperature was allowed to drift to $34^{\circ} \pm 1^{\circ} \mathrm{C}$. Rewarming to $38^{\circ} \mathrm{C}$ was begun during the construction of the proximal anastomoses, which was performed during a single prolonged crossclamp period. A left internal thoracic artery graft was anastomosed to the left anterior descending coronary artery as the last distal graft in all patients.
Table I. Patient demographics

\begin{tabular}{lccc}
\hline & $\begin{array}{c}\text { Low flow } \\
(\%)\end{array}$ & $\begin{array}{c}\text { High flow } \\
(\%)\end{array}$ & $\begin{array}{c}p \\
\text { Value }\end{array}$ \\
\hline $\begin{array}{l}\text { No. patients } \\
\text { Age (yr) }\end{array}$ & 9 & 10 & \\
Triple-vessel disease & $61 \pm 8$ & $58 \pm 8$ & 0.422 \\
$\begin{array}{l}\text { Double-vessel disease } \\
\text { LV ejection fraction }\end{array}$ & $3(67)$ & $10(100)$ & 0.087 \\
$\quad$ & & $0(0)$ & \\
$\quad 60 \%$ & $1(11)$ & $3(30)$ & 0.326 \\
$40 \%-59 \%$ & $8(89)$ & $6(60)$ & \\
$20 \%-39 \%$ & $0(0)$ & $11(10)$ & \\
$<20 \%$ & $0(0)$ & $0(0)$ & \\
Left main disease & $0(0)$ & $2(20)$ & 0.474 \\
Diabetes mellitus & $6(67)$ & $4(40)$ & 0.370 \\
Peripheral vascular disease & $0(0)$ & $1(10)$ & 0.330 \\
Hypertension & $4(44)$ & $4(40)$ & 0.845 \\
\hline
\end{tabular}

Cardioplegic technique. Patients were randomly assigned to either high or low flow cardioplegic delivery before operation with a computer-generated randomization table. All patients received a tepid $\left(29^{\circ} \mathrm{C}\right)$ blood cardioplegic solution that was prepared by mixing four parts of oxygenated blood with one part of a crystalloid solution ${ }^{18}$ and delivered with the Buckberg system (Sorin Inc., Irvine, Calif.). Cardiac arrest was achieved with an antegrade infusion of $500 \mathrm{ml}$ of high-potassium (30 $\mathrm{mEq} / \mathrm{L}$ ) cardioplegic solution given at a flow rate between 200 and $400 \mathrm{ml} / \mathrm{min}$ sufficient to maintain the aortic root pressure at $70 \mathrm{~mm} \mathrm{Hg}$. After this infusion, the aortic root was vented and retrograde delivery of cardioplegic solution began through an autoinflatable coronary sinus cannula (Research Medical, Midvale, Utah). Coronary sinus pressures were monitored continuously by a separate pressure-monitoring line and maintained at less than 40 $\mathrm{mm} \mathrm{Hg}$ throughout the procedure. The initial retrograde flow rate in all patients was $100 \mathrm{ml} / \mathrm{min}$. After completion of the distal anastamosis of the vein graft to the right coronary artery, biochemical measurements were obtained at a retrograde flow rate of $100 \mathrm{ml} / \mathrm{min}$. Retrograde perfusion was then modified to include simultaneous antegrade infusions into the completed right coronary artery graft, first at a flow rate of $100 \mathrm{ml} / \mathrm{min}$ and then at $200 \mathrm{ml} / \mathrm{min}$ in all patients. After a 1-minute timed perfusion at each flow rate, simultaneous retrograde and vein graft infusions were continued at the flow rate specified by the randomization table. This protocol discriminated the effect of retrograde cardioplegia alone, the addition of a single vein graft at a flow rate of $100 \mathrm{ml} / \mathrm{min}$, and the effect of increasing the flow rate to $200 \mathrm{ml} / \mathrm{min}$. Timed collections of the effluent from the aortic root were also measured as indicated in Fig. 1.

Measurements of myocardial metabolism. Arterial and coronary sinus blood samples were assayed to estimate the myocardial consumption of oxygen and production of lactate or acid. During periods of retrograde perfusion, effluent from the aortic root was used as a source of coronary venous blood. Oxygen content $\left(\mathrm{O}_{2} \mathrm{Con}\right)$ was calculated from the formula: 


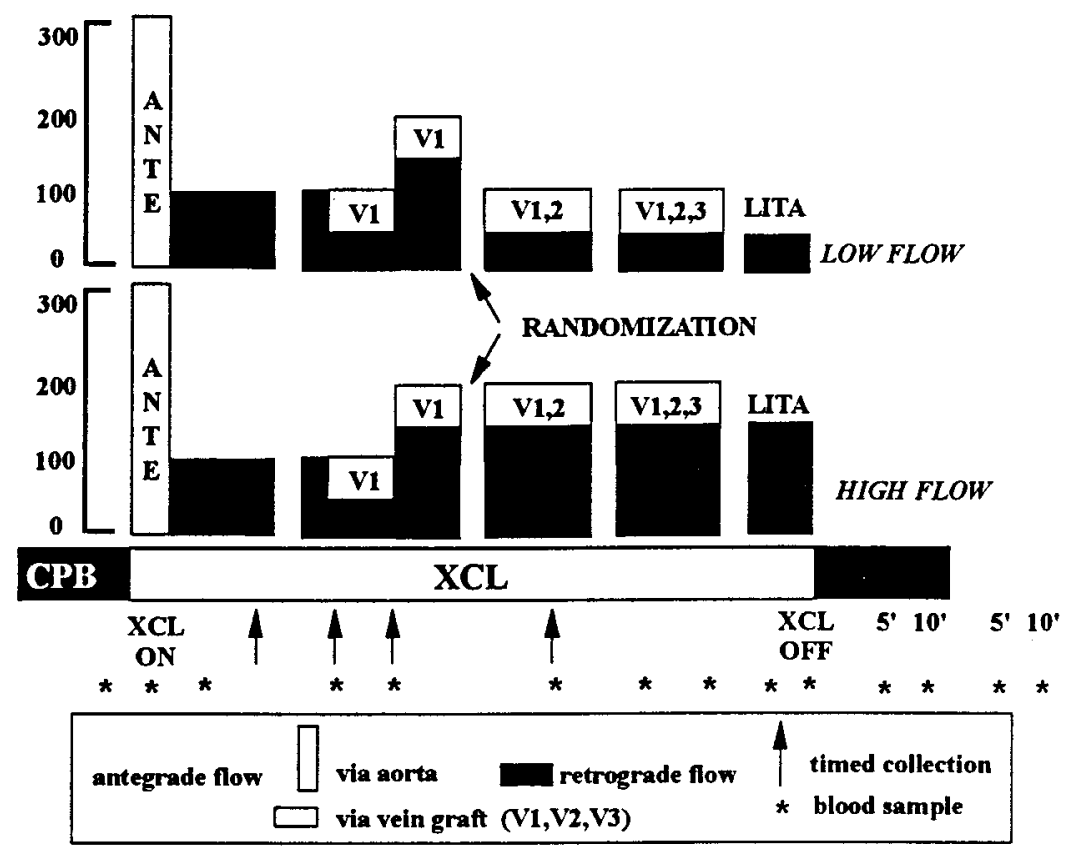

Fig. 1. Study protocol for comparing flow rates. After antegrade arrest by way of the aortic root, continuous retrograde delivery was instituted through the coronary sinus at a flow rate of $100 \mathrm{ml} / \mathrm{min}$. Cardioplegic flow was interrupted whenever necessary to visualize the distal anastomosis. After completion of the first distal anastomosis, the cardioplegic solution was delivered both retrogradely and antegradely into the vein graft at a flow rate of $100 \mathrm{ml} / \mathrm{min}$ for 1 minute, then at $200 \mathrm{ml} / \mathrm{min}$ for 1 minute. Simultaneous antegrade and retrograde delivery of the cardioplegic solution was then given at either low $(100 \mathrm{ml} / \mathrm{min})$ or high $(200 \mathrm{ml} / \mathrm{min})$ flow for the remainder of the procedure. $X C L$, Aortic crossclamp; $C P B$, cardiopulmonary bypass; LITA, left internal thoracic artery.

$\mathrm{O}_{2} \mathrm{Con}=1.39 \mathrm{Hgb} \times \mathrm{SaO}_{2}+0.0031 \times \mathrm{Po}_{2}$

where $\mathrm{Hgb}$ is the hemoglobin concentration, $\mathrm{SaO}_{2}$ is the oxygen saturation, and $\mathrm{PO}_{2}$ is the partial pressure of oxygen. Myocardial oxygen extraction $\left(\mathrm{O}_{2}\right.$ Ex) was calculated as the arterial or cardioplegic oxygen content minus the coronary effluent oxygen content and myocardial oxygen consumption $\left(\mathrm{MVO}_{2}\right)$ determined after correcting for coronary flow $\left(\mathrm{MVO}_{2}=\mathrm{O}_{2} \mathrm{Ex} \times\right.$ flow $)$. Measurements were made at $37^{\circ} \mathrm{C}$ and then corrected to the cardioplegic temperature at the time of sampling.

Blood lactate concentration was determined with the use of a commercially available assay (Rapid Lactate Stat Pack kit, Calbiochem-Behring, La Jolla, Calif.). Lactate extraction (LEx) was calculated as the difference between arterial and coronary effluent lactate content. Negative lactate extraction is expressed as net lactate release. Lactate consumption or production (MVL) was determined after correcting lactate extraction for coronary flow.

The concentration of hydrogen ion $\left[\mathrm{H}^{+}\right]$in blood was determined by converting the measured $\mathrm{pH}$ value to $\left[\mathrm{H}^{+}\right]$ by the formula: $\left[\mathrm{H}^{+}\right]=$Antilog $(-\mathrm{pH})$. Measurements were made at $37^{\circ} \mathrm{C}$ and corrected to the myocardial temperature at the time of sampling. Myocardial acid production was calculated as the difference in $\mathrm{H}^{+}$concentration between arterial and coronary effluent blood corrected for coronary flow.
Creatine kinase measurement. An antibody inhibition technique was used to measure the $\mathrm{MB}$ isozyme of creatine kinase (CK-MB). Sequential CK-MB measurements were performed at 2, 4, 8, 16, 24, and 48 hours after the removal of the aortic crossclamp. Integration of the area under the concentration-time curve for CK-MB within the first 48 hours postoperatively allowed calculation of the total CK-MB release, expressed as units $(\mathrm{IU} \times \mathrm{hr})$. We have previously found that this assessment correlates with infarction as assessed by technetium pyrophosphate scan. ${ }^{19}$

Hemodynamic measurements. Heart rate, mean arterial pressure, and mean pulmonary artery pressure were measured preoperatively and postoperatively. Cardiac output was measured in triplicate via a thermodilution technique by an independent individual who was unaware of the cardioplegic technique used. Derived hemodynamic indices were calculated:

$$
\begin{aligned}
& \mathrm{CI}=\mathrm{CO} / \mathrm{BSA}\left(\mathrm{L} / \mathrm{min} / \mathrm{m}^{2}\right) \\
& \mathrm{SI}=\mathrm{CI} / \mathrm{HR}\left(\mathrm{ml} / \mathrm{min} / \mathrm{m}^{2}\right)
\end{aligned}
$$

$\mathrm{LVSWI}=\mathrm{SI} \times(\mathrm{MAP}-\mathrm{PCWP}) \times 0.0316\left(\mathrm{gm} \cdot \mathrm{m} / \mathrm{m}^{2}\right)$

$\mathrm{SVRI}=(\mathrm{MAP}-\mathrm{RAP}) \times 80 / \mathrm{CI}\left(\right.$ dyne $\left.\cdot \mathrm{sec} / \mathrm{cm}^{5}\right)$ 
where $C I=$ cardiac index, $B S A=$ body surface area, $S I=$ stroke index, $L V S W I=$ left ventricular stroke work index, and $S V R I=$ systemic vascular resistance index.

These hemodynamic variables were measured before initiation of cardiopulmonary bypass and at 2, 4, 8, and 24 hours after removal of the aortic crossclamp. Postoperative preload and afterload were optimized by individuals who were unaware of the cardioplegic technique used. ${ }^{20}$

Statistical analysis. Statistical analysis was performed using the SAS program (SAS Institute, Cary, N.C.). Categorical variables were analyzed with $\chi^{2}$ or Fisher's exact test as appropriate. Continuous variables were analyzed using analysis of variance (ANOVA) or paired $t$ tests as appropriate. A two-way ANOVA was used to simultaneously evaluate the effect of time and flow rate between groups. When the $F$ statistic of the two-way ANOVA was significant, differences between groups were specified by Duncan's multiple range test. Statistical significance was assumed at $p<0.05$.

\section{Results}

Table II presents the operative data. No significant differences were found in the number of grafts constructed, the aortic crossclamp time, or the total cardiopulmonary bypass time. All 10 patients in the high flow group received an initial saphenous vein graft to the right coronary artery or one of its branches compared with eight of nine patients in the low flow group. Despite an increased flow rate in the high flow group, the total volume of cardioplegic solution delivered did not differ between groups $(p=0.749)$. Similarly, the volume of effluent in the aortic root measured during the last 1-minute timed collection was not different between groups. The volume of effluent in the aortic root did not increase significantly when the flow rate was increased to 200 $\mathrm{ml} / \mathrm{min}$ (low $85 \pm 19 \mathrm{ml}$ vs high $116 \pm 45 \mathrm{ml}, p=$ 0.217 ). When the volume of cardioplegic solution delivered was adjusted for the aortic crossclamp time, total cardioplegic delivery was higher in the high flow group $(114 \pm 22 \mathrm{ml} / \mathrm{min}$ vs low $84 \pm 18$ $\mathrm{ml} / \mathrm{min}, p=0.005)$. Similarly, cardioplegic delivery per bypass graft was also higher in the high flow group $(1677 \pm 365 \mathrm{ml} /$ graft vs low $1264 \pm 239$ $\mathrm{ml} / \mathrm{graft}, p=0.01)$. Ischemic time expressed as the percentage of the crossclamp period during which no cardioplegic solution was given was not different between groups. Minimum cardioplegic temperatures were similar in both groups (low $34^{\circ} \pm 0.5^{\circ} \mathrm{C}$ vs high $35^{\circ} \pm 0.1^{\circ} \mathrm{C}, p=0.616$ by two-way ANOVA).

No deaths, strokes, or perioperative myocardial infarctions occurred in this low-risk study population. One patient in the high flow group had low cardiac output syndrome because he required ino-
Table II. Operative data

\begin{tabular}{|c|c|c|c|}
\hline & $\begin{array}{c}\text { Low flow } \\
(n=9)\end{array}$ & $\begin{array}{l}\text { High flow } \\
(n=10)\end{array}$ & $p$ Value \\
\hline LIMA & $9(100 \%)$ & $10(100 \%)$ & 1.000 \\
\hline \multicolumn{4}{|l|}{ Grafts } \\
\hline Three & $2(22 \%)$ & $0(0 \%)$ & 0.198 \\
\hline Four & $2(22 \%)$ & $5(50 \%)$ & \\
\hline Five & $5(56 \%)$ & $5(50 \%)$ & \\
\hline Pump time (min) & $86 \pm 15$ & $85 \pm 12$ & 0.862 \\
\hline Crossclamp time (min) & $66 \pm 13$ & $66 \pm 12$ & 0.989 \\
\hline $\begin{array}{l}\text { Total cardioplegic so- } \\
\text { lution delivered (ml) }\end{array}$ & $5168 \pm 1314$ & $5550 \pm 2879$ & 0.749 \\
\hline $\begin{array}{l}\text { Average cardioplegic } \\
\text { return in aortic root } \\
(\mathrm{ml} / \mathrm{min})\end{array}$ & $82 \pm 20$ & $89 \pm 48$ & 0.655 \\
\hline $\begin{array}{l}\text { Percentage of cross- } \\
\text { clamp time without } \\
\text { cardioplegia }\end{array}$ & $31 \pm 6$ & $33 \pm 9$ & 0.544 \\
\hline $\begin{array}{l}\text { Area under the } \\
\text { CKMB curve } \\
(\mathrm{IU} \cdot \mathrm{hr})\end{array}$ & $1747 \pm 724$ & $1331 \pm 1198$ & 0.475 \\
\hline Myocardial infarction & 0 & 0 & 1.000 \\
\hline Low-output syndrome & 0 & 1 & 0.330 \\
\hline Stroke & 0 & 0 & 1.000 \\
\hline Operative mortality & 0 & 0 & 1.000 \\
\hline
\end{tabular}

tropic support for greater than 30 minutes in the intensive care unit to maintain systolic blood pressure greater than $90 \mathrm{~mm} \mathrm{Hg}$ and a cardiac index of $2.1 \mathrm{~L} / \mathrm{min}$ per square meter or greater. Perioperative myocardial injury estimated by the area under the CK-MB curve was not different between groups.

Metabolic data. Myocardial oxygen consumption, lactate, and acid production were similar in both groups after antegrade arrest. Table III illustrates myocardial oxygen extraction, lactate, and acid release before aortic crossclamping, after antegrade arrest, during the first retrograde dose (at a flow rate of $100 \mathrm{ml} / \mathrm{min}$ ), and during reperfusion. No differences were demonstrated between groups.

Fig. 2 illustrates the change in myocardial oxygen consumption, lactate, and acid production after the completion of the right coronary artery graft. Tepid retrograde cardioplegia alone resulted in an accumulation of hydrogen ions that was washed out after the addition of simultaneous antegrade perfusion into the right coronary artery graft. Increasing the flow rate from $100 \mathrm{ml} / \mathrm{min}$ to $200 \mathrm{ml} / \mathrm{min}$ resulted in a further washout of lactate and hydrogen ions with a corresponding increase in myocardial oxygen consumption.

During the crossclamp period, high cardioplegic flows resulted in greater lactate release. Similarly, myocardial acid release was higher in the high flow 
Table III. Perioperative metabolic data

\begin{tabular}{|c|c|c|c|}
\hline & $\begin{array}{c}\text { Low flow } \\
(n=9)\end{array}$ & $\begin{array}{l}\text { High flow } \\
(n=10)\end{array}$ & $p$ Value \\
\hline \multicolumn{4}{|l|}{ Baseline } \\
\hline Oxygen extraction $(\mathrm{dl} / \mathrm{ml})$ & $2.9(0.5)$ & $3.1(0.5)$ & 0.836 \\
\hline Lactate extraction $(\mathrm{mmol} / \mathrm{ml})$ & $-0.3(0.3)$ & $0.2(0.1)$ & 0.139 \\
\hline Acid release $(\Delta \mathrm{pH})$ & $0.05(0.01)$ & $0.06(0.01)$ & 0.561 \\
\hline \multicolumn{4}{|l|}{ Antegrade arrest } \\
\hline Oxygen extraction (dl/ml) & $3.0(0.7)$ & $2.6(0.4)$ & 0.638 \\
\hline Lactate extraction $(\mathrm{mmol} / \mathrm{ml})$ & $-0.1(0.2)$ & $-0.1(0.2)$ & 0.982 \\
\hline Acid release $(\Delta \mathrm{pH})$ & $0.09(0.03)$ & $0.12(0.02)$ & 0.310 \\
\hline \multicolumn{4}{|l|}{ Initial retrograde $(100 \mathrm{ml} / \mathrm{min})$} \\
\hline Oxygen extraction $(\mathrm{dl} / \mathrm{ml})$ & $0.3(0.1)$ & $0.2(0.1)$ & 0.665 \\
\hline Lactate extraction $(\mathrm{mmol} / \mathrm{ml})$ & $-0.3(0.2)$ & $-0.6(0.1)$ & 0.187 \\
\hline Acid release $(\Delta \mathrm{pH})$ & $0.01(0.01)$ & $0.05(0.01)$ & 0.003 \\
\hline \multicolumn{4}{|c|}{ Retrograde and first vein graft $(100 \mathrm{ml} / \mathrm{min})$} \\
\hline Oxygen extraction $(\mathrm{dl} / \mathrm{ml})$ & $0.4(0.4)$ & $0.4(0.4)$ & .522 \\
\hline Lactate extraction $(\mathrm{mmol} / \mathrm{ml})$ & $-0.6(0.3)$ & $-0.8(0.3)$ & .628 \\
\hline Acid release $(\Delta \mathrm{pH})$ & $0.08(0.01)$ & $0.08(0.01)$ & .961 \\
\hline \multicolumn{4}{|l|}{ Aortic crossclamp removal } \\
\hline Oxygen extraction $(\mathrm{dl} / \mathrm{ml})$ & $1.2(0.3)$ & $2.0(0.5)$ & 0.213 \\
\hline Lactate extraction $(\mathrm{mmol} / \mathrm{ml})$ & $0.1(0.1)$ & $-0.2(0.1)$ & 0.144 \\
\hline Acid release $(\Delta \mathrm{pH})$ & $0.03(0.01)$ & $0.05(0.01)$ & 0.317 \\
\hline \multicolumn{4}{|l|}{ Reperfusion (5 min) } \\
\hline Oxygen extraction $(\mathrm{dl} / \mathrm{ml})$ & $3.9(0.5)$ & $4.2(0.5)$ & 0.761 \\
\hline Lactate extraction $(\mathrm{mmol} / \mathrm{ml})$ & $-0.1(0.1)$ & $-0.1(0.1)$ & 0.522 \\
\hline Acid release $(\Delta \mathrm{pH})$ & $0.06(0.01)$ & $0.07(0.01)$ & 0.642 \\
\hline \multicolumn{4}{|l|}{ Reperfusion $(10 \mathrm{~min})$} \\
\hline Oxygen extraction $(\mathrm{dl} / \mathrm{ml})$ & $5.5(0.5)$ & $5.0(0.4)$ & 0.466 \\
\hline Lactate extraction $(\mathrm{mmol} / \mathrm{ml})$ & $0.1(0.1)$ & $0.1(0.1)$ & 0.991 \\
\hline Acid release $(\Delta \mathrm{pH})$ & $0.05(0.01)$ & $0.07(0.01)$ & 0.148 \\
\hline
\end{tabular}

group. Acid washout decreased throughout the crossclamp period, resulting in no significant differences between groups after completion of the fourth distal anastomosis. Similarly, myocardial oxygen consumption was higher in the high flow group, but this difference dissipated as additional vein grafts became perfused. Fig. 3 illustrates the difference in metabolite washout between the two groups.

Hemodynamic data. Postoperative heart rate was increased compared with baseline, whereas the mean arterial pressure fell, but no differences were found between groups in heart rate or mean arterial pressure either before or after surgery. Fig. 4 displays the postoperative hemodynamic data obtained at 2, 4, 8, and 24 hours after the removal of the aortic crossclamp. Cardiac index and left ventricular stroke work index were higher in the high flow group 2 hours postoperatively at similar filling pressures $(p<0.05$ by analysis of covariance [ANOCOVA] $)$.

\section{Discussion}

Despite apparently adequate blood cardioplegic protection, sensitive measures reveal delayed recov- ery of myocardial metabolism and ventricular function. ${ }^{7,8}$ This impairment may be due to inhomogeneous distribution of cardioplegic solution during either antegrade or retrograde cardioplegia alone. ${ }^{21}$ An integrated cardioplegic technique using both antegrade and retrograde delivery has been advocated by many authors. ${ }^{11-16}$ However, the optimal flow rate required to improve myocardial perfusion when using integrated cardioplegia is not known. We previously found that a flow rate of less than 200 $\mathrm{ml} / \mathrm{min}$ during normothermic $\left(37^{\circ} \mathrm{C}\right)$ retrograde cardioplegia resulted in an accumulation of lactate and acid during the crossclamp period. ${ }^{17}$ Flow rates in excess of $200 \mathrm{ml} / \mathrm{min}$ did not result in further washout of toxic metabolites. However, flow rates of $200 \mathrm{ml} / \mathrm{min}$ may be detrimental if they result in high coronary sinus pressures. A coronary sinus pressure of greater than $40 \mathrm{~mm} \mathrm{Hg}$ has been reported to result in perivascular hemorrhage and edema, as well as direct coronary sinus injury. ${ }^{22}$

Lowering the temperature from $37^{\circ} \mathrm{C}$ to $29^{\circ} \mathrm{C}$ reduced myocardial oxygen consumption by almost $50 \% .{ }^{10}$ Therefore a $50 \%$ reduction in flow rate from 


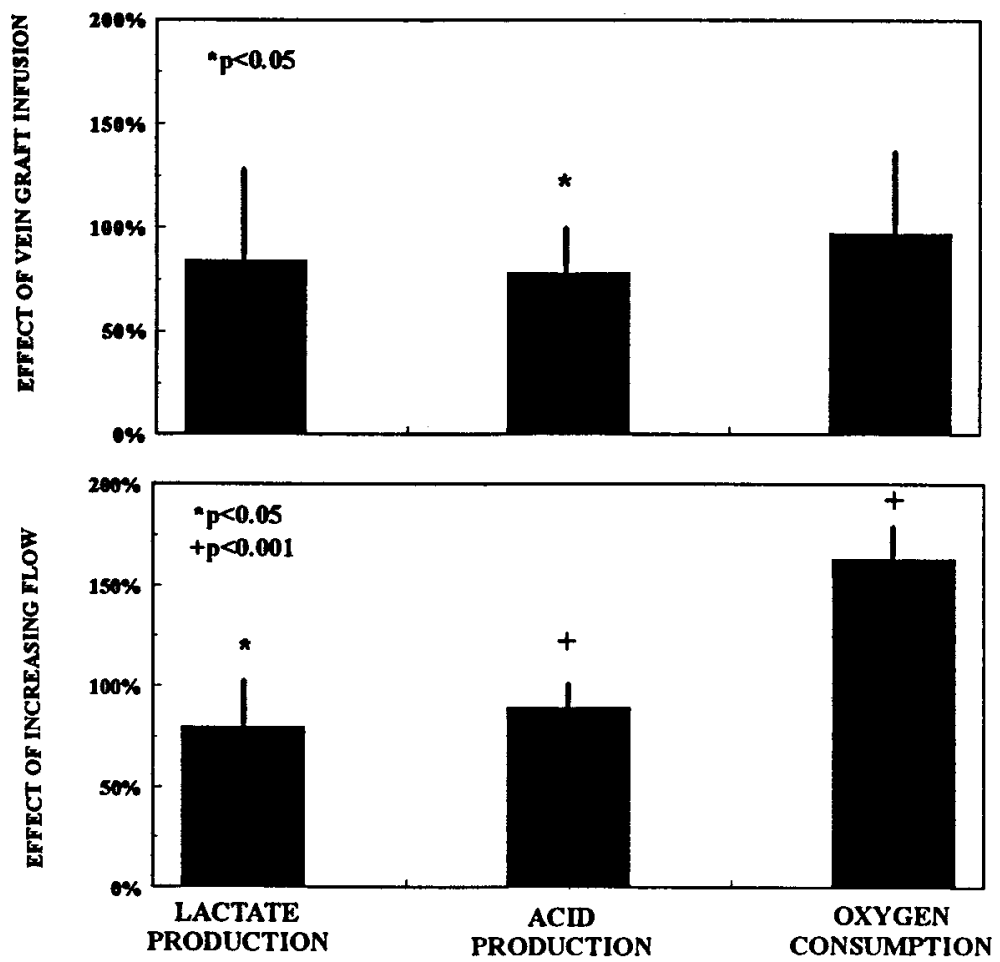

Fig. 2. Top panel, Percent change in lactate and acid production and oxygen consumption after the addition of antegrade cardioplegic perfusion into the completed right coronary artery graft. Bottom panel, Percent change in lactate and acid production and oxygen consumption achieved by increasing the flow rate from $100 \mathrm{ml} / \mathrm{min}$ (low) to $200 \mathrm{ml} / \mathrm{min}$ (high). Myocardial oxygen consumption significantly increased as the flow rate increased. Similarly, increasing the cardioplegic flow rate significantly increased lactate and acid washout.

$200 \mathrm{ml} / \mathrm{min}$ to $100 \mathrm{ml} / \mathrm{min}$ may not be detrimental at a myocardial temperature of $29^{\circ} \mathrm{C}$. This study was undertaken to determine the optimal flow rate for integrated tepid $\left(29^{\circ} \mathrm{C}\right)$ blood cardioplegia and is the first report to investigate flow rates with this increasingly popular cardioplegic technique.

At $29^{\circ} \mathrm{C}$, retrograde flows of $100 \mathrm{ml} / \mathrm{min}$ were inadequate to maintain homogeneous myocardial perfusion. The addition of a single vein graft resulted in increased washout of lactate and acid. Most patients (18 of 19) received an initial graft to the right coronary artery or one of its distal branches. Increasing the flow rate from 100 to 200 $\mathrm{ml} / \mathrm{min}$ resulted in a further washout of toxic metabolites. We believe that the increased flow rate led to improved myocardial perfusion. When perfusion was improved by additional antegrade infusions into completed vein grafts, the effect of flow rate was attenuated. Thus anaerobic metabolism was stimulated by inadequate myocardial perfusion that was prevented by either increasing the flow rates or by the addition of simultaneous vein graft infusions.

We were able to deliver a flow rate of $200 \mathrm{ml} / \mathrm{min}$ in all 10 patients in the high flow group with a coronary sinus pressure less than $40 \mathrm{~mm} \mathrm{Hg}$. We used a single pump head to deliver cardioplegic solution into the coronary sinus cannula and the vein grafts simultaneously. Possibly, increases in coronary sinus pressure may have resulted in increased flow down the vein grafts. It is also possible that higher flow rates (in excess of $250 \mathrm{ml} / \mathrm{min}$ ) may be better than our high-flow technique. We did not examine this possibility in our study. We did find, however, that the effluent in the aortic root during a 1-minute timed collection was not different between groups. The variability in this measurement likely reflects the variability in thebesian shunt flow. Thus increasing flow rates beyond $200 \mathrm{ml} / \mathrm{min}$ during integrated cardioplegic delivery may increase the shunt fraction as we observed with retrograde cardioplegia alone. ${ }^{17}$ 

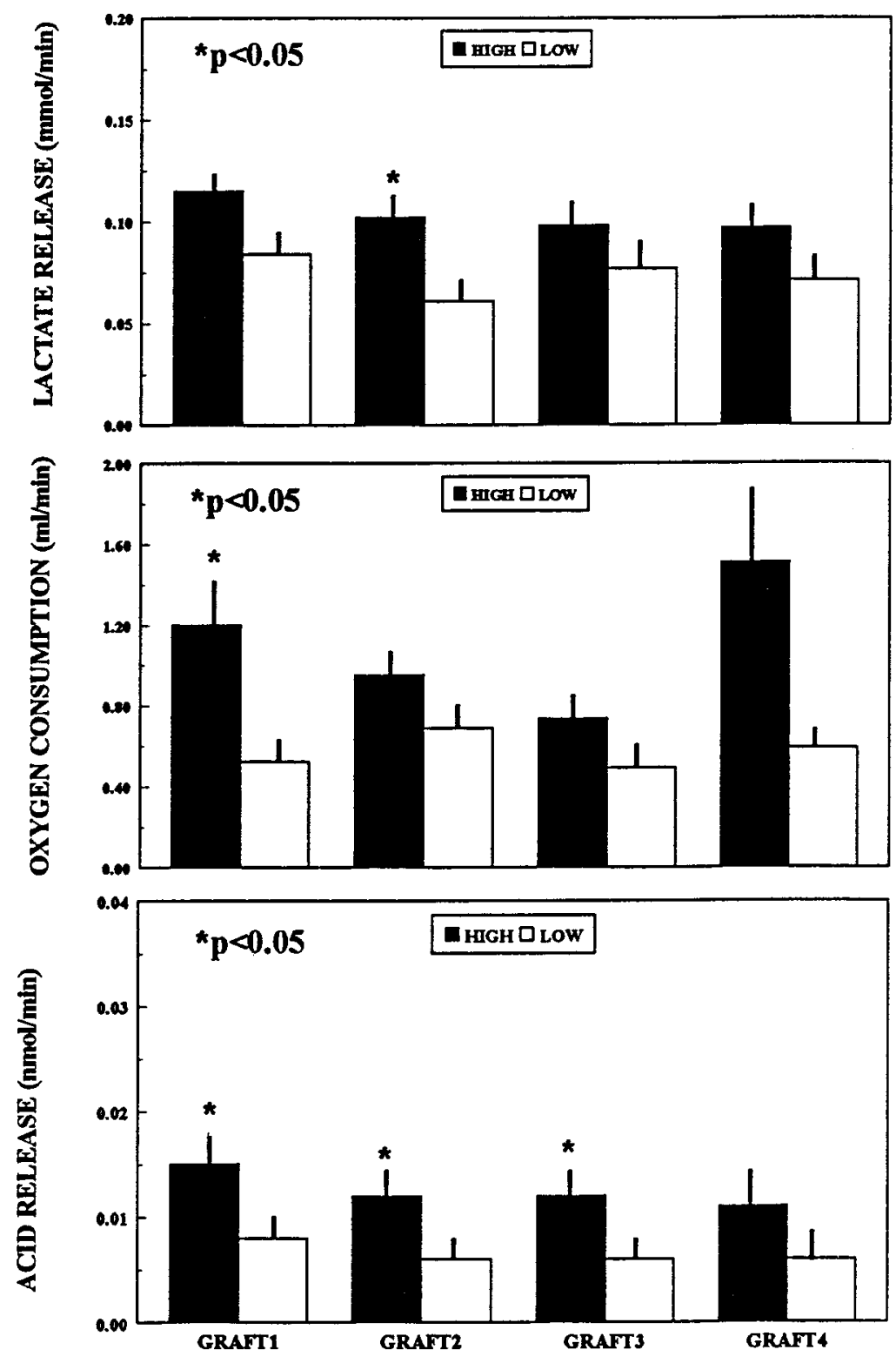

Fig. 3. Panel A, Myocardial lactate release after completion of each distal anastomosis. Washout of accumulated lactate was higher in patients receiving high cardioplegic flow rates after the second distal anastomosis. The difference between high and low flow rates dissipated as additional vein grafts became perfused ( $p=0.088$ by two-way ANOVA). Panel B, Myocardial oxygen consumption after completion of each distal anastomosis. Oxygen consumption was higher in patients receiving high cardioplegic flow rates after the first distal anastomosis. This difference dissipated as additional vein grafts became perfused $(p=$ 0.158 by two-way ANOVA). Panel $C$, Myocardial acid release after completion of each distal anastomosis. Washout of accumulated hydrogen ions was higher in patients receiving high cardioplegic flow rates $(p=$ 0.034 by two-way ANOVA) (mean \pm standard error of the mean).

The improved myocardial perfusion in the high flow group improved early postoperative hemodynamics. Fig. 4 illustrates that at a given preload (left ventricular end-diastolic pressure), cardiac index and left ventricular stroke work index were higher in the high flow group. No differences were observed between groups in clinical outcomes. Our study population consisted of low-risk patients with excel- 


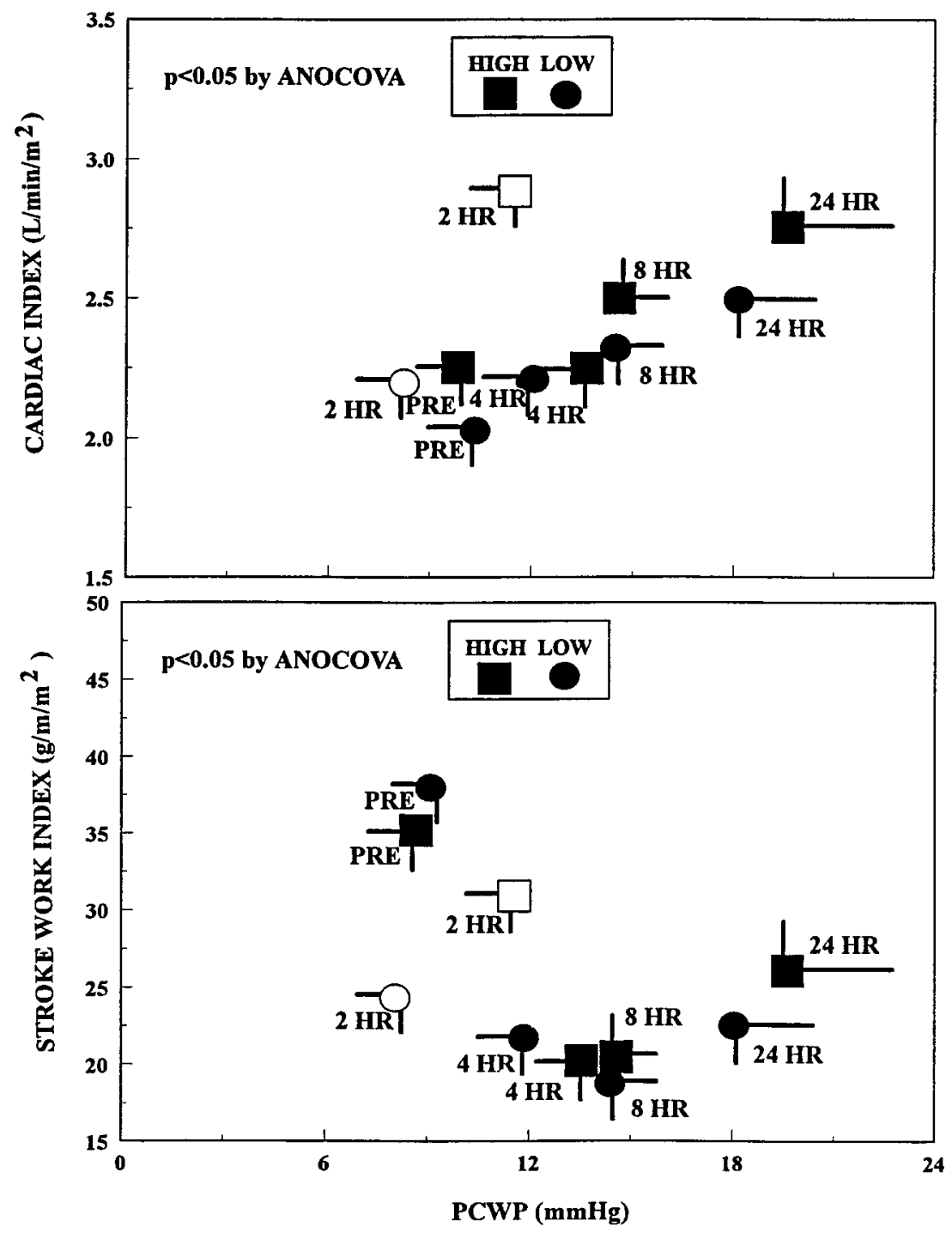

Fig. 4. Panel $A$, Cardiac index at baseline (PRE), 2, 4, 8, and 24 hours postoperatively. Cardiac index was greater in the high flow group (hollow symbols; $p=0.03$ by ANOCOVA). LVEDP, Left ventricular end-diastolic pressure (mm Hg). Panel B, Left ventricular stroke work index (LVSWI) at baseline (PRE), $2,4,8$, and 24 hours postoperatively. LVSWI was greater in the high flow group (hollow symbols; $p=0.05$ by ANOCOVA). PCWP, Pulmonary capillary wedge pressure ( $\mathrm{mm} \mathrm{Hg}$ ).

lent collateral circulation and preserved left ventricular function, and clinical differences were not anticipated.

Study limitations. Coronary venous blood obtained from the aortic root during retrograde delivery of cardioplegic solution is contaminated by noncoronary collateral blood flow from the pulmonary veins. Contamination is further exacerbated by simultaneous vein graft perfusions that may deliver oxygenated blood cardioplegic solution into the aortic effluent. These sources of contamination tend to decrease both lactate and acid concentrations while increasing oxygen tensions in the aortic effluent. Therefore our measurements of myocardial washout underestimate the true accumulation of lactate and acid in ischemic myocardium. Coronary blood flow during cardioplegic arrest was assumed to be equivalent to cardioplegic flow rate. Variability in the thebesian shunt fraction at different flow rates also confounds these measurements. 
Despite these limitations, we were able to detect subtle differences in myocardial metabolism during cardioplegic arrest. Our ability to detect differences in metabolite washout despite significant contamination suggests an even larger difference between high- and low-flow groups. Furthermore, the significant improvement in left ventricular function 2 hours after crossclamp removal suggests that improved myocardial protection was achieved at higher flow rates.

Coronary blood flow was not measured during reperfusion. Therefore our inability to detect metabolic differences during reperfusion may be a result of differences in coronary blood flow that may have masked true differences in metabolic activity.

Our technique of "continuous" retrograde delivery of blood cardioplegic solution required interruption for more than $30 \%$ of the crossclamp period to adequately visualize the distal anastomosis. Maintaining "continuous" flow throughout the crossclamp period may have reduced the accumulation of toxic metabolites that we observed in this study. However, we believe that is more prudent to ensure a technically proficient distal anastomosis and continue to interrupt cardioplegic delivery whenever necessary. When interruptions are necessary, a flow rate of 200 $\mathrm{ml} / \mathrm{min}$ is required to ensure adequate washout of the accumulated metabolites.

\section{Summary}

We conclude from this study that flow rates of $100 \mathrm{ml} / \mathrm{min}$ are inadequate when using an integrated, tepid blood cardioplegic approach to myocardial protection. We have previously demonstrated that subtle metabolic and hemodynamic differences of the magnitude found in this study correlate with differences in clinical outcomes in higher risk populations, such as those patients who require surgery for unstable angina. ${ }^{23,24}$ Therefore in high-risk patients flow rates less than $200 \mathrm{ml} / \mathrm{min}$ may increase the incidence of postoperative morbidity and mortality. The possible benefits of increasing flow rates beyond $250 \mathrm{ml} / \mathrm{min}$ requires further investigation.

We acknowledge the valuable assistance of the nurses in the cardiac operating room and intensive care unit. In addition, we recognize the participation of the cardiac perfusionists at The Toronto Hospital, without whom these studies would not be possible. The biochemical expertise of M. K. Mohabeer and L. C. Tumiati is greatly appreciated.

\section{REFERENCES}

1. Gott VL, Gonzalez JL, Zuhdi MN, et al. Retrograde perfusion of the coronary sinus for direct-vision aortic surgery. Surg Gynecol Obstet 1957;104:319.

2. Partington MT, Acar C, Buckberg GD, et al. Studies of retrograde cardioplegia. I. Capillary blood flow distribution to myocardium supplied by open and occluded arteries. J Thorac Cardiovasc Surg 1989;97:605-12.

3. Menasche P, Subayi JB, Veyssie L, et al. Efficacy of coronary sinus cardioplegia in patients with complete coronary artery occlusions. Ann Thorac Surg 1991;51:418-23.

4. Quintillo C, Voci P, Bilotta F, et al. Risk factors for incomplete distribution of cardioplegic solution during coronary artery grafting. J Thorac Cardiovasc Surg 1995;109:43947.

5. Rudis E, Gates RN, Laks H, et al. Coronary sinus ostial occlusion during retrograde delivery of cardioplegic solution significantly improves cardioplegic distribution and efficacy. J Thorac Cardiovasc Surg 1995;109:941-7.

6. Menasche P. Experimental comparison between manually inflatable versus autoinflatable retrograde cardioplegia catheters. Ann Thorac Surg 1994;58:533-5.

7. Yau TM, Weisel RD, Mickle DAG, et al. Alternative techniques of cardioplegia. Circulation 1992; 86(Suppl):II377-84.

8. Yau TM, Ikonomidis JS, Weisel RD, et al. Ventricular function after normothermic versus hypothermic cardioplegia. J Thorac Cardiovasc Surg 1993;105:833-44.

9. Maatsura H, Lazar HL, Yang XM, et al. Detrimental effects of interrupting warm blood cardioplegia during coronary revascularization. J Thorac Cardiovasc Surg 1993;106:357-61.

10. Hayashida N, Ikonomidis JS, Weisel RD, et al. The optimal cardioplegic temperature. Ann Thorac Surg 1994;58:961-71.

11. Bhayana JN, Kalmbach T, Booth FV, et al. Combined antegrade/retrograde cardioplegia for myocardial protection: a clinical trial. J Thorac Cardiovasc Surg 1989;98:956-60.

12. Drinkwater DC, Laks H, Buckberg GD. A new simplified method of optimizing cardioplegic delivery without right heart isolation: antegrade/retrograde blood cardioplegia. J Thorac Cardiovasc Surg 1990;100:56-63.

13. Kalmbach T, Bhayana JN. Cardioplegic delivery by combined aortic root and coronary sinus perfusion. Ann Thorac Surg 1989;47:316-7.

14. Hayashida N, Weisel RD, Shirai T, et al. Tepid antegrade and retrograde cardioplegia. Ann Thorac Surg 1995;59:723-9.

15. Hayashida N, Ikonomidis JS, Weisel RD, et al. Adequate distribution of warm cardioplegic solution. J Thorac Cardiovasc Surg 1995;110:800-12.

16. Shirai T, Rao V, Weisel RD, et al. Antegrade and retrograde cardioplegia: Simultaneous or alternate? J Thorac Cardiovasc Surg 1996;112:787-96.

17. Ikonomidis JS, Yau TM, Weisel RD, et al. Optimal flow rates for retrograde warm cardioplegia. J Thorac Cardiovasc Surg 1994;107:510-9.

18. Yau TM, Weisel RD, Mickle DAG, et al. Optimal delivery of blood cardioplegia. Circulation 1991;84(Suppl):III380-8.

19. Burns RJ, Gladstone PJ, Tremblay PC, et al. Myocardial infarction determined by technetium- $99 \mathrm{~m}$ pyrophosphate single-photon tomography complicating elective coronary artery bypass grafting for angina pectoris. Am J Cardiol 1989;63:1429-34.

20. Weisel RD, Burns RJ, Baird RJ, et al. Optimal postoperative volume loading. J Thorac Cardiovasc Surg 1983;85:552-63. 
21. Rao V, Ikonomidis JS, Weisel RD, et al. Inhomogeneous retrograde cardioplegia. Can J Cardiol 1994;10:85C.

22. Panos AL, Ali IS, Birnbaum PL, Barrozo CA, Al-Nowaiser $\mathrm{O}$, Salerno TA. Coronary sinus injuries during retrograde continuous, normothermic blood cardioplegia. Ann Thorac Surg 1992;54:1137-8.
23. Christakis GT, Fremes SE, Weisel RD, et al. Reducing the risk of urgent revascularization for unstable angina: a randomized clinical trial. J Vasc Surg 1986;3:764-72.

24. Teoh KH, Mickle DAG, Weisel RD, et al. Improving myocardial metabolic and functional recovery after cardioplegic arrest. J Thorac Cardiovasc Surg 1988;95:788-98. 